\title{
Trabalhadores de saúde como protagonistas de um processo de construção do perfil de competências
}

\author{
Health workers as protagonists of a competency profile \\ building process
}

Los trabajadores de la salud como protagonistas de un proceso de creación de un perfil de competencias

\author{
Mara Lúcia Renostro ZACHI ${ }^{(1)}$ \\ Elaine Rossi RIBEIRO ${ }^{(2)}$ \\ Maria Lúcia da SILVA ${ }^{(3)}$ \\ Rogério Saad $V A Z^{(2)}$
}

Recebido: 4 jun 2019

Revisado: 17 dez 2019

Aceito: 10 jan 2020

Autor de

correspondência:

Elaine Rossi Ribeiro

elaine.rossi@hotmail.com

Conflito de interesses:

Os autores declaram não haver nenhum interesse profissional ou pessoal que possa gerar conflito de interesses em relação a este manuscrito.

\footnotetext{
${ }^{(1)}$ Centro Universitario FAG, Secretaria Municipal de Saúde , Cascavel, PR, Brasil.

(2) Faculdade Pequeno Princípe, Curitiba, PR, Brasil.

${ }^{(3)}$ Secretaria de Saúde do Estado, Londrina, PR, Brasil.
}

\section{Resumo}

As crescentes mudanças gerenciais e tecnológicas, ocorridas na área da saúde, bem como as mudanças demográficas e o perfil epidemiológico, exigem dos profissionais que coordenam as Unidades de Saúde um perfil de competências mais flexível e adaptativo. $O$ estudo teve como objetivo construir o perfil de competências dos coordenadores de Unidades de Saúde. Trata-se de uma pesquisa de caráter exploratório descritivo, com abordagem qualitativa, da qual participaram os profissionais da Secretaria de Saúde de um município do Paraná, sendo um total de vinte participantes. A coleta de dados ocorreu com a técnica de grupos focais, com a participação de cinco pessoas em cada um dos quatro grupos. Os dados foram analisados segundo a técnica de análise de conteúdo, na modalidade temática. Foram identificados os núcleos temáticos que surgiram nas discussões dos grupos, elencadas as unidades de sentido e as suas respectivas categorias. Diante dos resultados advindos dos grupos focais, apresenta-se uma matriz de competência para a função de coordenador de Unidade de Saúde. A matriz está organizada da seguinte forma: as competências de cada núcleo temático delimitam a intenção do trabalho, determinando a atuação do coordenador e, para cada competência, é apresentado um conjunto de desempenhos. Esta descreve um leque de capacidades e habilidades, que resultam uma boa prática gerencial do coordenador de Unidades de Saúde, referenciada em critérios de excelência. As combinações de capacidades e os critérios de excelência ética, estética e científica determinam a qualidade da sua atuação. Podem ser utilizados em várias combinações e estilos singulares de gestão, produzindo resultados de sucesso, porém, sempre ancorados no perfil de competência esperado.

Descritores: Competência Profissional; Atenção Primária à Saúde; Educação em Saúde; Sistema Único de Saúde. 


\begin{abstract}
The increasing managerial and technological changes occurring in health area, as well as demographic changes and epidemiological profile, require professionals who coordinate the Health Units a more flexible and adaptive competency profile. The purpose of this study was to build the competency profile of Health Unit coordinators. This is a descriptive exploratory research with a qualitative approach, where professionals from Health Department of one Parana Municipality participated in the study, being a total of twenty participants. Data collection took place through focus groups technique, with the participation of five people in each of the four groups. Data were analyzed according to the technique of content analysis, in the thematic modality. The thematic nuclei that emerged in discussions of groups were identified, indicating the units of meaning and their respective categories. Given the results of the focus groups, a competency matrix is presented for the role of coordinator of Health Unit. The matrix is organized as follows: The competencies of each thematic core delimit the intention of the work, determining the coordinator's performance, and for each competency a set of performances is presented. This describes a range of skills and abilities that result in a good managerial practice of the Coordinator of Health Units referenced in criteria of excellence. The combinations of capabilities and the criteria of ethical, aesthetic and scientific excellence determine the quality of their performance. They can be used in several combinations and unique management styles, producing successful results, but always anchored in the expected competency profile.
\end{abstract}

Keywords: Professional Competence; Primary Health Care; Health Education; Unified Health System.

\title{
Resumen
}

Los crecientes cambios gerenciales y tecnológicos ocurridos en el área de la salud, así como los cambios demográficos y el perfil epidemiológico, exigen de los profesionales que coordinan las Unidades de Salud un perfil de competencias más flexible y adaptativo. El estudio tuvo como objetivo construir el perfil de competencias de los coordinadores de Unidades de Salud. Se trata de una investigación de carácter exploratorio descriptivo con abordaje cualitativo, donde participaron del estudio los profesionales de la Secretaría de Salud de un municipio de Paraná, siendo un total de veinte participantes. La recolección de datos ocurrió con la técnica de grupos focales, con la participación de cinco personas en cada uno de los cuatro grupos. Los datos fueron analizados según la técnica de análisis de contenido, en la modalidad temática. Se identificaron los núcleos temáticos que surgieron en las discusiones de los grupos, enumeradas las unidades de sentido y sus respectivas categorías. En el caso de los grupos focales, se presenta una matriz de competencia para la función de coordinador de Unidad de Salud. La matriz está organizada de la siguiente forma: Las competencias de cada núcleo temático delimitan la intención del trabajo, determinando la actuación del coordinador y para cada competencia se presenta un conjunto de resultados. Esta describe una gama de capacidades y habilidades que resultan en una buena práctica gerencial del coordinador de Unidades de Salud referenciada en criterios de excelencia. Las combinaciones de capacidades y los criterios de excelencia ética, estética y científica, determinan la calidad de la actuación de esos. Pueden ser utilizados en varias combinaciones y estilos singulares de gestión, produciendo resultados de éxito, pero siempre anclados en el perfil de competencia esperado.

Palabras-claves: Competencia Profesional; Atención Primaria de Salud; Educación en Salud; Sistema Único de Salud.

\section{Introdução}

A vivência da pesquisadora com o trabalho de gestão nas Unidades de Saúde incitou a uma reflexão sobre o processo de mudanças que essa função vem sofrendo, desde a implantação do Sistema Único de Saúde - SUS até a importância de estabelecer um perfil diferenciado para os profissionais que exercem essas atividades, as quais se ampliam no cotidiano do trabalho. 
No contexto organizacional do SUS, o coordenador das Unidades de Saúde destacase como um ator eficaz na condução dos processos assistenciais, pois, no esboço de seu papel, estão inscritas ações relacionadas ao espaço interno e externo das Unidades de Saúde, para atender às demandas de saúde de uma população que, hoje, é detentora de maiores informações, com maiores exigências e igualmente maiores necessidades. ${ }^{1}$ Essas ações não se referem, já há algum tempo, apenas ao papel do coordenador como um mero fiscalizador da equipe; essa função amplia-se para um efetivo desempenho, exercendo de maneira sistêmica a gestão de pessoas e o gerenciamento de recursos físicos, materiais e financeiros, o aprimoramento dos sistemas de comunicação e informação intra e interinstitucional, com a população e comunidade acadêmica.

Percebe-se que a condução do processo de trabalho gerencial nas Unidades de Saúde é uma das atividades mais importantes para a qualificação da assistência prestada aos usuários do SUS. Mas, ao mesmo tempo, identifica-se que existem muitos modos e estilos de coordenar esses serviços, que geram questionamentos e muitas divergências no modo de condução do trabalho, ficando evidente o quão é importante a construção de um perfil de competências para os trabalhadores que exercem essa função.

Em uma análise crítico-reflexiva dessa vivência pessoal, com a prática gerencial nas Unidades de Saúde, observa-se que os comportamentos e características pessoais, bem como os conhecimentos prévios e as bagagens que cada um traz consigo, interferem favorável ou desfavoravelmente nos processos decisórios. Desse modo, optou-se por realizar um estudo cuja questão norteadora foi: quais competências são necessárias para um coordenador de Unidade de Saúde desempenhar adequadamente sua função de gestão?

Diante disso, o objetivo do estudo é construir o perfil de competências dos coordenadores das Unidades de Saúde, analisar a percepção dos coordenadores quanto às competências necessárias para atuar na coordenação das unidades e mapear o conhecimento, habilidades e atitudes necessárias, visando à construção do perfil de competências.

Para Junqueira, ${ }^{2}$ a formação dos profissionais da saúde não é suficiente para caracterizar um bom gestor nos serviços de saúde brasileiros; principalmente no setor público, são encontradas ineficiência e baixa qualidade nessa atividade, de maneira a sugerir que esse baixo desempenho pode ser atribuído à inexistência de um perfil de competência, bem como à falta de um programa de educação permanente, voltado para o desenvolvimento de capacidades; outro fator são os baixos salários e a falta de condições de trabalho. ${ }^{2}$ 
A partir da década de 1980, os serviços de saúde iniciaram a incorporação de novas ferramentas gerenciais, inspiradas na indústria, para a direção dos processos de trabalho, alterando o perfil definido para que o profissional de saúde possa atuar na gestão, a fim de dialogar com a prática da gestão por competências. A partir dessa nova formulação, as competências profissionais passam a ser valorizadas, uma vez aliadas aos processos educacionais que qualificam essa prática. ${ }^{3}$

Os autores Bittencourt ${ }^{4}$ e Ruas et al. ${ }^{5}$ enfatizam que o desenvolvimento de competências deve abordar três dimensões: o saber, referente ao conhecimento, é necessário para realizar o trabalho com qualidade; o saber fazer, que se refere às habilidades, o que deveria ser conhecido para um bom desempenho; e o saber agir, que está relacionado às atitudes necessárias para colocar em prática os conhecimentos e habilidades.

Para a descrição adequada de uma competência, é necessário que ela represente um comportamento que indique o que o profissional deve ser capaz de fazer, o que é esperado desse profissional. Tal comportamento deve ser descrito, utilizando-se um verbo e um objeto de ação, podendo acrescentar uma condição sempre que possível, na qual se espera que o desempenho ocorra; por fim, incluir um critério, indicando um padrão de qualidade ou nível de desempenho satisfatório do profissional. ${ }^{6}$

Dessa forma, é preciso identificar um conjunto de conhecimentos, habilidades e atitudes, solicitadas aos trabalhadores pelas instituições, que introduzem novas tecnologias associadas ao paradigma da produção flexível e integrada. Incluem-se, nesse caso, os serviços de saúde que vêm exigindo cada vez mais uma atitude flexível e uma reinvenção da prática dos trabalhadores para atender às necessidades de saúde da população e à mudança para um modelo de atenção à saúde centrado nas pessoas. Destaca-se a valorização das atitudes e comportamentos considerados importantes nesse modelo para um melhor aproveitamento da força de trabalho.

\section{Metodologia}

Trata-se de um estudo de caráter exploratório, descritivo, com abordagem qualitativa. A amostra do estudo foi composta por 16 coordenadores de unidades de saúde da Secretaria Municipal de Saúde de um município do Paraná, dois coordenadores de distrito sanitário, um Diretor do Departamento de Atenção à Saúde e um Gerente da Divisão de Gestão de Pessoas, totalizando 20 participantes na pesquisa. Como técnica de coleta de dados, foi utilizado o grupo focal ou focusgroup, considerada uma técnica de pesquisa qualitativa direta, que possibilita a compreensão e construção das percepções, atitudes e representações sociais de grupos acerca de um tema específico. Segundo Godim, ${ }^{7}$ a técnica 
de grupo focal é utilizada como fonte principal e suplementar de dados, tanto para subsidiar trabalhos de intervenção quanto para elaborar instrumentos de pesquisa exploratória e qualitativa; além disso, como fonte complementar de dados, ao serem associados às técnicas de entrevistas em profundidade e de observação participante. As origens dos grupos de foco estão pautadas na diversidade dos métodos de comportamento científico e na psicoterapia.

Essas técnicas foram desenvolvidas por Robert K. Merton e descritas em um livro em coautoria com Patrícia L. Kendall, em 1946; um dos atributos principais da entrevista focal é o fato dos entrevistados serem expostos a situações concretas já conhecidas pelo entrevistador, nas quais são apresentados estímulos relacionados ao tema, participando de um experimento psicológico, ou seja, é uma abordagem científica que aproxima o pesquisador do contexto psicológico e social dos entrevistados com o objetivo de interpretar melhor suas ações. ${ }^{8}$

A escolha da técnica foi favorecida por ser rápida e de baixo custo para avaliação e obtenção de dados e informações qualitativas. Além disso, fornece ao pesquisador uma grande riqueza de informações qualitativas sobre o desempenho de atividades desenvolvidas pelos gerentes e coordenadores, bem como das competências necessárias para o cargo.

Para a análise e tratamento dos dados, foi utilizada a técnica proposta por Bardin, ${ }^{9}$ que se caracteriza pela interpretação do material de caráter qualitativo, garantindo uma descrição sistemática, objetiva e com a riqueza do conteúdo exposta no momento da coleta. A matriz do perfil de competências dos coordenadores foi construída a partir das informações coletadas, entendendo, após a discussão, à luz do referencial teórico, a relevância das competências identificadas a serem melhor descritas. A partir dessa reflexão, buscou-se adaptar ao referencial de Carbone et al., ${ }^{6}$ fazendo a sincronização do conhecimento com as habilidades. O projeto da pesquisa foi submetido ao Comitê de Ética em Pesquisa da Faculdade Pequeno Príncipe - FPP (CEP FPP/PR), o qual foi aprovado sob o número do protocolo CAAE: 61551416.5.0000.5580.

\section{Resultados e Discussão}

O material produzido nos encontros grupais foi analisado, estabelecendo conexões entre a percepção dos coordenadores de unidades de saúde, gerentes, diretor da atenção básica e assessor da gestão estratégica, em relação às competências necessárias para a função de coordenador de unidade de saúde. Isso, tendo em vista a construção de uma 
matriz de competências para o profissional que exerce essa função na Secretaria de Saúde do Município.

O material dos grupos foi gravado e transcrito e, na sequência, foram realizadas várias leituras flutuantes de todo o material, com o intuito de apreender e organizar, de forma não estruturada, aspectos importantes para as próximas fases da análise. Na leitura flutuante, o contexto dos discursos emergiu, de modo que foi possível agrupar os dados considerados relevantes e a parte comum existente entre eles, classificando-os por semelhança, que foi denominada como núcleos temáticos para a construção das categorias.

Mediante as falas identificadas nas discussões, foram definidos quatro núcleos temáticos, que se repetiram em todos os grupos focais, a saber: Competência de Gestão, Competência Comportamental, Competências Técnicas e Competência Organizacional. A partir de tais núcleos, identificaram-se unidades de sentido, que serão apresentadas e discutidas a seguir no Quadro 1.

Quadro1. Núcleos temáticos e unidades de sentido

\begin{tabular}{|c|c|}
\hline \hline Núcleos Temáticos & Unidades de Sentido \\
\hline Competência de Gestão & $\begin{array}{c}\text { Educação } \\
\text { Planejamento } \\
\text { Liderança } \\
\text { Resolutividade } \\
\text { Mediação }\end{array}$ \\
\hline Competência Comportamental & Comunicação \\
\hline Competências Técnicas & Relacionamento Interpessoal \\
\hline Competência Organizacional & Conhecimento de Gestão \\
& Conhecimento de Gestão de Pessoas \\
\hline \hline
\end{tabular}

Fonte: Elaborado pelos autores (2018).

\section{Educação}

Os grupos elencaram os processos educacionais como um importante desafio para o coordenador, conforme mostram os fragmentos tirados dos discursos dos participantes, ilustrando esse desafio:

[...] o coordenador deveria saber o papel de cada um dos profissionais, seria interessante reunir os profissionais em um plano de educação permanente para compartilhar experiências e conhecimentos (C2). 
Seria bom se nos coordenadores tivéssemos um espaço coletivo para compartilharmos nossas dificuldades e experiências, um espaço de educação permanente para os próprios coordenadores (C8).

Portanto, o que se evidencia nos discursos é que, em algumas poucas experiências, existe uma aposta em espaços de democratização nos serviços, por exemplo, as reuniões de equipe, espaços que permitem a construção do conhecimento, da interação e da troca, em que os trabalhadores podem compartilhar conhecimentos entre si; em outros espaços, em que o usuário participa e há troca de conhecimentos com os trabalhadores, experiências que têm trazido resultados significativos; são experiências bem isoladas, com iniciativas de uma ou duas pessoas, conforme relato dos participantes da pesquisa.

Para produzir mudanças no processo de gestão no trabalho na $A B$, na prática das equipes e no controle social, é essencial dialogar com as práticas e os princípios do SUS, de forma a problematizá-los, não de maneira subjetiva, mas no trabalho concreto de cada equipe e nos espaços grupais de interação entre elas, na comunidade e na gestão, construindo novos significados e acordos de organização, além de melhorias no processo de trabalho. ${ }^{10}$

Para isso, é necessário que esse profissional, o qual assume o papel de liderança da equipe, desenvolva também competências na área educacional. Dessa forma, o teórico e sociólogo Perrenoud, ${ }^{11}$ que é uma grande referência no campo da Educação, com seus trabalhos desenvolvidos em torno das competências dos educadores, nos traz um referencial importante, no sentido de que é possível que esses profissionais desenvolvam competências necessárias ao ensino. O autor defende, para os processos de ensino e aprendizagem, uma metodologia baseada na pedagogia ativa, compartilhada e colaborativa, com a participação ativa de todos os profissionais na construção do conhecimento. Propõe, nesse caso, o desenvolvimento e compreensão de dez grandes famílias de competências: 1) organizar e dirigir situações de aprendizagem; 2) administrar a progressão das aprendizagens; 3) conceber e fazer com que os dispositivos de diferenciação evoluam; 4) envolver os alunos em suas aprendizagens e em seu trabalho; 5) trabalhar em equipe; 6) participar da administração da escola; 7) informar e envolver os pais; 8) utilizar novas tecnologias; 9) enfrentar os deveres e os dilemas éticos da profissão; 10) administrar a própria formação contínua.

Assim, o objetivo desta reflexão teórica é pensar sobre as dez competências necessárias aos coordenadores, que também assumem o papel de educadores, propostas por Perrenoud, as quais podem ser amplamente aplicáveis nesse campo da educação permanente das equipes de $A B$. 


\section{Mediação}

$\mathrm{Na}$ discussão dos grupos, os coordenadores expressaram a preocupação de desenvolver capacidades para lidar com os conflitos que surgem no cotidiano do trabalho das equipes, como ilustram os recortes dos discursos a seguir:

Gerenciar conflito é um desafio para o coordenador, acho sempre melhor resolver logo, não deixar o conflito criar grandes proporções, mas precisamos passar por uma reciclagem para poder gerenciar melhor os conflitos (C2).

Percebe-se, também, diante desses discursos, que não existe um preparo do coordenador para lidar com os conflitos inerentes ao trabalho, promovendo na equipe momentos de planejamento, de discussão de casos de construção coletiva das práticas do cuidado. Lidar com os conflitos é inerente ao trabalho do coordenador, que precisa comunicar e orientar as mudanças, escutar novas demandas, ampliar a capacidade de análise crítica e reflexiva nos coletivos.

Para Merhy ${ }^{12}$ no cotidiano do trabalho das equipes, existe um movimento de disputa que é claramente definido por várias visões bem distintas. Disputa-se não só o modo de se construir coletivamente as práticas de saúde, mas também, como fazê-las. Essas disputas produzem diversos desafios para o trabalho coletivo e a gestão dele, gerando diversos conflitos com a equipe e usuários.

\section{Planejamento}

O tema planejamento, exposto nas discussões dos grupos, é percebido pelos coordenadores como uma estratégia da gestão importante para superar a rotina, promover a atenção programática e a motivação dos profissionais, além da integração dos membros da equipe, como demonstra a fala a seguir:

Percebo que para atuar melhor na coordenação precisamos trabalhar com planejamento, a curto, médio e longo prazo, ser mais proativo, ficamos preenchendo papel e apagando incêndio, isso nos desmotiva (C2).

As falas dos participantes balizaram como a falta de planejamento - para aquelas situações que são apontadas como insuficiência na gestão - faz com que o coordenador gaste grande parte de seu tempo "apagando incêndio". Na compreensão desses trabalhadores, ações burocráticas, como "papelada", as diversas planilhas e indicadores, que precisam ser alimentadas com os dados, dificultam o processo de planejamento das ações com a equipe. Mas, entendem que o emprego do planejamento estratégico em saúde pode ser incorporado às ações da equipe, melhorando o processo de trabalho e 
implementando as ações programadas, de forma a reduzir os atendimentos na demanda espontânea.

\section{Resolutividade}

A capacidade resolutiva também foi um ponto de discussão nos grupos focais, apresentada como uma competência necessária para o coordenador da unidade, como ilustramos na fala a seguir:

O coordenador precisa ser resolutivo e isso não é fácil dentro da complexidade do trabalha que realizamos nas unidades, isso tudo é muito complexo, às vezes não sei por onde começar é muita cobrança e as coisas não dependem sozinhos dependemos dos outros senviços da rede (C5).

A resolutividade da $A B$ supõe dois aspectos: a capacidade de absorver o número de assistência solicitada e a capacidade de resolver os casos atendidos. ${ }^{13}$ É nesse contexto que o acesso dos usuários à rede de atendimento teria que se dar por meio das US; os trabalhadores deveriam estar qualificados para atender e resolver cerca de $80 \%$ dos problemas de saúde dos usuários que a eles recorrem.

\section{Comunicação}

Um aspecto importante nas discussões foi a expressividade com que a competência de comunicação surgiu na discussão nos grupos, com destaque para sua importância no papel do coordenador. Atribuíram essa importância à objetividade, à clareza, ao discernimento do profissional de saber se colocar de forma coerente, efetivando a compreensão, além de escolher os momentos certos e local adequado, de acordo com a demanda de cada situação. O trecho da fala a seguir expõe a percepção do coordenador em relação a uma boa comunicação.

A Comunicação é muito importante, acho que o mal da humanidade é a falta da comunicação sem ela nada acontece, porém muitas vezes da forma que ela é feita, mais atrapalha do que ajuda. (C7)

Utilizar estratégias para uma boa comunicação, com uma população ou um grupo de indivíduos, para a transferência de informações, não abrange somente aspectos do cognitivo, mas também, aspectos sociais, éticos e políticos, tendo como objetivo diminuir a distância que existe entre uma parte da sociedade que conhece e outra que não conhece ou conhece pouco. Existe uma preocupação de atenuar o poder conferido ao saber, que, na nossa sociedade, é um instrumento de dominação e de 
promoção de hierarquia social, o que ocasiona as discriminações e as injustiças sociais. 14

\section{Relacionamento Interpessoal}

Nos discursos, verifica-se que existe uma preocupação com as relações no trabalho, buscando perceber as emoções das pessoas como um meio de aproximação, de se manter a cordialidade, respeito e empatia, refletindo também a preocupação com a humanização em relação à equipe, mas não só com ela, com os usuários também, acolhendo todas as necessidades e lidando com diversos sentimentos, como: frustrações, medos e incertezas. Na fala a seguir, é possível perceber tal preocupação.

O coordenador tem que saber se relacionar com todo mundo, com o gestor, a equipe e a população, porque ele é o elo entre os três, quando tem algum problema todos recorrem a ele. (C20) Precisa também ter um bom relacionamento com todos os serviços da rede, porque ele sempre acaba precisando deles (C19).

Sobre a atuação interdisciplinar dos trabalhadores, Moscovici ${ }^{15}$ apresenta dois tipos de competências importantes: uma está ligada ao desempenho técnico de cada um e a outra é a competência interpessoal, entendida como a habilidade de se relacionar com outras pessoas, envolvendo o acolhimento das diferenças e diversas percepções.

$\mathrm{Na}$ área técnica, os grupos discursaram sobre a importância de ter conhecimentos específicos, para que saibam direcionar o trabalho das equipes; identificaram a necessidade de ter conhecimento na área de gestão e gestão de pessoas.

\section{Conhecimentos na Área de Gestão}

O trabalho é a essência de tudo; está relacionado com o que se faz para o bom funcionamento dos serviços e é o que traz uma maior efetividade na produção do cuidado. Portanto, conhecê-lo e compreendê-lo é um requisito fundamental para a consolidação do SUS e suas práticas. As falas dos participantes, apresentadas a seguir, demostram essa necessidade:

[...] não conhecia nada sobre gestão antes de assumir a coordenação, fui descobrindo sozinha como fazer [...]

Acho muito importante a gente ter um espaço dos coordenadores onde podemos aprender juntos sobre vários temas, tipo um grupo de estudo, onde pudéssemos trocar experiência" (C4). 
Existem experiências isoladas no SUS de implantação ou implementação desses espaços de EPS, de discussão e construção do conhecimento, de maneira participativa e humanizada, partindo do pressuposto de que as singularidades da realidade e dos diversos atores são importantes para o desenvolvimento do processo. Isso mostra que é possível construir processos de trabalho efetivos e apropriados aos profissionais e usuários. ${ }^{16}$

\section{Conhecimento na Área de Gestão de Pessoas}

Essa competência foi evidenciada em todos os grupos, expondo as dificuldades de se abordar e lidar com as relações interpessoais e interprofissionais no serviço, frente a tantas outras demandas que congestionam o dia a dia dos coordenadores. Estes, por sua vez, não conseguem enxergar e valorizar a dimensão do trabalho de cada um, oferecendo feedbacks adequados e construtivos.

acho que ter a competência de lidar com a gestão de pessoas é a parte mais difícil, temos que lidar com muitos conflitos, profissionais despreparados, sem perfil para a ESF, fazemos o que podemos, também não temos formação para lidar com gestão de pessoas"

Alguns aspectos importantes para desenvolver as capacidades na gestão de pessoas na $A B$ também foram destacados nos grupos, a saber: uma gestão mais horizontalizada possível; promover um ambiente de trabalho de construção coletiva e gestão compartilhada; manter e ampliar o máximo possível à autonomia da equipe; manter a equipe unida nas dificuldades que envolvem o processo do trabalho; compartilhar experiências e aprender juntos.

\section{Modelo de Cuidado Centrado no Usuário}

O modelo centrado no usuário é percebido pelos participantes da pesquisa como um desafio para os trabalhadores da saúde, envolvendo o processo de trabalho das equipes de $A B$, além de ser considerado um tema privilegiado para a produção do cuidado e à mudança do modelo de assistência, em que o foco são as pessoas. Dessa maneira, todos os participantes da pesquisa expressam essa compreensão.

[...] outra coisa importante na unidade é a escuta qualificada, você precisa escutar o usuário e entender a necessidade dele (C3).

É importante parar para escutar com atenção a necessidade do usuário (C2).

Ë muito mais fácil você lidar com algo pontual, do que lidar com o ser humano diante da sua complexidade, suas diferenças, a necessidade de cada um, requer tempo, paciência, jeito (C5). 


\section{Integração dos serviços}

Diante das reflexões que ocorreram nos grupos, em relação à integração dos serviços, em torno da capacidade das equipes de ofertar uma atenção continuada, observou-se que algumas equipes têm desenvolvido ações de territorialização, cadastramento da população, ações, de vigilância em saúde, atendimentos, visitas domiciliares, consultas médicas, de enfermagem e odontológicas, procurando ofertar uma gama de procedimentos para atender à necessidade dos usuários, respeitando suas singularidades.

Porém, o desafio está ainda na integralidade do cuidado, quando o usuário, para ter suas necessidades de saúde atendidas, precisa de um conjunto de serviços, ao qual chamamos de redes de atenção à saúde; esses serviços devem estar disponíveis sempre que o usuário precisar.

Acontece que, segundo a fala dos participantes da pesquisa, nem sempre esses serviços estão disponíveis para o usuário no momento em que necessita. Ilustramos isso com a fala do coordenador:

Às vezes encaminhamos o usuário, mas a fila para o atendimento na especialidade é enorme, sabemos que vai demorar, aí sobra para nós coordenadores ficar ligando e tentando um atendimento, porque o usuário sempre retorna pra unidade (C5).

\section{Matriz de competências}

Diante dos resultados apreendidos dos grupos focais, apresenta-se uma matriz de competência. A matriz está organizada da seguinte forma: as competências de cada núcleo temático delimitam a intenção do trabalho, determinando a atuação do coordenador e, para cada competência, é apresentado um conjunto de desempenhos. Para fins de apresentação, neste artigo, apenas haverá o apontamento dos desempenhos para cada competência, advinda dos quatro núcleos temáticos, a saber:

Núcleo temático "Competência de Gestão":

A) Articular politicamente, buscando integração entre Unidade/Secretaria, parceria com conselho local de saúde, na busca de melhorias para a unidade, promovendo educação em saúde na comunidade, participando da educação em saúde na comunidade, além de incentivá-la a participar do conselho local de saúde e promover articulação com os diversos pontos de atenção da rede.

B) Cumprir as atividades inerentes à função com responsabilidade, assiduidade e organização, comprometimento com os princípios da atenção primária em saúde e com a saúde da população, assegurando o bom funcionamento dos equipamentos, além de solicitar inspeções periódicas dos profissionais que 
manipulam os equipamentos; realizar a Gestão com foco em liderança, identificando o potencial e a maturidade dos profissionais da equipe, com o objetivo de definir o grau de autonomia que cada um terá ao desempenhar suas atividades; mobilizar a equipe em direção a um objetivo, delegando e acompanhando o desenvolvimento de cada um, orientando-se pelo momento do profissional, de forma a utilizar a escuta e um bom diálogo, o que descentraliza a tomada de decisões, com equidade, ponderação, agilidade e raciocínio lógico; considerar todas as possibilidades de ação, focando o alcance das metas e antevendo os resultados, o que desenvolve dispositivos de Educação Permanente, que possibilitem a reflexão sobre os processos de trabalho e a produção das mudanças necessárias às práticas de saúde. Construir espaços coletivos de trabalhadores e usuários para a discussão da qualificação da assistência.

C) Avaliar o processo de trabalho, responsabilizando os profissionais, com impessoalidade e profissionalismo, elogiando, quando necessário, mas também chamando a atenção e advertindo por escrito, conforme normas da Secretaria; incentivar os profissionais a aprender com os erros.

D) Ser mediador e facilitador nos processos, promovendo espaços coletivos, demonstrando capacidade de orientação e estímulo ao aprendizado de outras pessoas; conduzir atividades educacionais para a equipe e população, fazendo e recebendo críticas, de modo ético e respeitoso, o que visa reconhecer as conquistas, estimular o desenvolvimento das pessoas, diminuindo as falhas no trabalho.

Núcleo temático "Competência Comportamental":

A) Ser comunicativo, desenvolvendo meios de comunicação internos e externos eficientes e transparentes, bem como noticiar aos usuários as atividades desenvolvidas na unidade, buscando a satisfação do usuário do serviço de saúde; fornecer feedbacks à equipe e à gestão, sabendo ouvir, com o foco completamente no que a outra pessoa está dizendo e no que ela não está dizendo; oferecer apoio para que a pessoa se expresse, promovendo na equipe ampliação da capacidade de escuta e de comunicação como os usuários; interagir com as diversas pessoas, com uma negociação, de forma assertiva e ética, respeitando os diversos interesses, além de demonstrar habilidades e técnicas avançadas de comunicação e articulação com os profissionais, os gestores e a população em geral. 
B) Agir de acordo com os princípios da ética e bioética nas relações com o usuário, a família e a equipe de saúde, acolhendo os usuários de forma humanizada; esclarecer as dúvidas dos usuários em relação ao cuidado prestado, promovendo na equipe a privacidade e o sigilo em relação às informações dos pacientes.

C) Ser cordial, demonstrando a capacidade de ser e prestativo com outras pessoas, educado e seguindo os protocolos de uma boa comunicação.

D) Ser criativo, organizando os conhecimentos e realizando suas atividades de forma inovadora e inventiva; criar um jeito novo de resolver problemas inesperados, bem como usar ideias criativas no aperfeiçoamento de seus processos de trabalho, tendo empatia e flexibilidade, além de desenvolver parcerias no processo gerencial; envolver-se com a população da área de abrangência da unidade e com a equipe, construindo uma relação de vínculo, adaptando-se às alterações; aceitar as mudanças, descobrindo novas oportunidades e entendendo todas as extensões sobre as quais terá impacto.

Núcleo Temático "Competência Técnica":

A) Elaborar documentos que contenham informações adequadas claras, concisas e objetivas, com conhecimento intermediário em informática, que favoreça o entendimento das situações para ações e decisões, utilizando diferentes softwares de gerenciamento e aplicativos vigentes.

B) Cumprir a legislação e as normas do SUS, com integralidade e imparcialidade; conhecer os direitos e deveres dos usuários e profissionais; conhecer a rede, as linhas guias e os fluxos ofertados pela secretaria e procurar disponibilizá-los aos usuários.

C) Conhecer a rede intersetorial e procurar disponibilizá-la aos usuários, considerando os equipamentos existentes no território de abrangência e no Município.

D) Conhecer as atribuições dos profissionais da equipe, estimular e avaliar a participação no processo de trabalho pela equipe, considerando as contribuições de cada um, as dificuldades e desafios, no desenvolvimento de práticas interdisciplinares e transdisciplinares, focadas na melhoria da qualidade da assistência.

Núcleo temático "Competência Organizacional": 
A) Conhecer e compreender as necessidades de saúde da população. Conhecer o território, fazendo uma leitura da realidade de saúde e das reais necessidades da população, identificando o conjunto de riscos inerentes e potenciais à saúde da população na área de abrangência da sua Unidade de Saúde.

B) Reconhecer e atuar sobre os componentes biológicos, subjetivos e sociais envolvidos na produção e um cuidado singular do processo saúde e doença, individual e coletivo; organizar o trabalho da produção do cuidado na coletividade, ampliando a capacidade de autocuidado e construir maiores níveis de autonomia em relação à situação de saúde; participar de modo compartilhado na construção de projetos terapêuticos, que utilizem as melhores evidências científicas e sejam capazes de lidar com a singularidade de cada caso individual e coletivo.

C) Apoiar a inserção de ações e serviços com caráter de promoção e prevenção à saúde, que se articulem com as ações de assistência e reabilitação para garantir a abordagem integral do processo saúde/doença.

D) Utilizar critérios de avaliação de risco e vulnerabilidade, bem como fatores de proteção, para identificação de prioridades na construção de projetos de intervenção.

A matriz traduz a síntese de capacidades que resultam numa boa prática gerencial do coordenador de Unidades de Saúde, referenciada em critérios de excelência. As combinações de capacidades e os critérios de excelência ética, estética e científica determinam a qualidade da sua atuação. Cabe, portanto, ressaltar que podem ser produzidas diferentes combinações e estilos singulares de gestão, produzindo resultados de sucesso, porém, sempre ancorados no perfil de competência esperado.

\section{Conclusão}

O estudo teve como objetivo construir um perfil de competência de coordenadores de Unidades de Saúde, a partir da análise e da percepção dos coordenadores quanto às competências necessárias para atuar na coordenação das unidades, dialogando com os autores e mapeando o conhecimento, habilidade e atitudes necessárias ao cargo.

Os resultados destacam que os grupos focais conseguiram expressar suas percepções sobre as competências essenciais ao coordenador de Unidades de Saúde; entre elas, evidenciaram-se as competências gerenciais, comportamentais, técnicas e organizacionais. 
O mapeamento do perfil de competências dos coordenadores, com o seu protagonismo, bem como o desenvolvimento das suas capacidades por meio de uma formação permanente, permite inovação e implementação de estratégias para um desempenho profissional que proporcione mudanças, as quais têm o caráter de transformar a realidade dos processos gerenciais na $A B$.

Com o desenvolvimento e a formação gerencial dos coordenadores, ampliam-se seus saberes, os quais poderão servir de referências, sendo aplicados no seu contexto de trabalho. Por conseguinte, contribuirão para o atendimento efetivo das necessidades de saúde da população, além de possibilitar uma melhor compreensão da realidade abordada e estabelecer estratégias mais adequadas de intervenções, tomada de decisões e gerenciamento de conflitos.

No que se refere à contribuição da pesquisa para avanços no processo de desenvolvimento de competências dos coordenadores, a matriz de competências potencialmente contribui para estimular novas políticas e práticas de gestão de pessoas na secretaria de saúde, à medida que se torna um instrumento para definir perfis esperados dos servidores da área, para subsidiar avaliações de desempenho, identificar as lacunas de competências, contribuindo à formação dos profissionais. Isso porque as competências elencadas podem servir como parâmetro de orientação para a Secretaria de Saúde, na elaboração do futuro Plano de Educação Permanente.

Espera-se incentivar e estimular reflexões sobre a relevância de transformações nos processos gerenciais da $A B$, a fim de que sejam refletidas na melhoria dos processos de trabalho e, consequentemente, na melhoria da assistência, além de provocar inquietações que resultem em novas pesquisas.

\section{Referências}

1. Alves M, Penna CMM, Brito MJM. Perfil dos gerentes de unidades básicas de saúde. Rev Bras Enferm. 2004;57(4):441-6. http://dx.doi.org/10.1590/S0034-71672004000400011.

2. Junqueira LAP. Gerência dos Serviços de Saúde. Cad Saude Publica. 1990;6(3):247-59. https://doi.org/10.1590/S0102-311X1990000300002.

3. Cunha ICKO, Ximenes Neto FR. Competências gerenciais de enfermeiras: um novo velho desafio?. Texto Contexto. 2006;15(3):479-82. https://doi.org/10.1590/S0104 07072006000300013.

4. Bitencourt CA. Gestão de competências gerenciais: a contribuição da aprendizagem organizacional [tese]. Porto Alegre: Universidade Federal do Rio Grande do Sul; 2001. 
5. Ruas RL, Antonello CS, Boff LH. Aprendizagem organizacional e competências. Porto Alegre: Bookman; 2005.

6. Carbone PP, Brandão HP, Leite JBD, Vilhena RMP. Competência e gestão do conhecimento (2a ed.). Rio de Janeiro: FGV; 2006.

7. Gondim SMG. Grupos focais como técnica de investigação qualitativa: desafios metodológicos. Paidéia (Ribeirão Preto). 2003;12(4):149-61. https://doi.org/10.1590/S0103-863X2002000300004.

8. Merton RK, Kendall PL. The focused interview. Am J Sociol. 1946;51(6):541-57. https://doi.org/10.1086/219886.

9. Bardin L. Análise de conteúdo. São Paulo: Edições 70; 2011.

10. Ministério da Saúde (BR). Curso de formação de facilitadores de educação permanente em saúde: unidade de aprendizagem: análise do contexto da gestão e das práticas de saúde. Rio de Janeiro: Fiocruz; 2005.

11. Perrenoud P. Dez novas competências para ensinar. Ramos PC, tradutora. Porto Alegre: Artmed; 2000.

12. Merhy E. Os desafios postos pela atenção gerenciada para pensar uma transição tecnológica do setor saúde. São Paulo: Hucitec; 2002. Saúde: a cartografia do trabalho vivo; p. 67-92.

13. Starfield B. Atenção Primária: equilíbrio entre necessidades de saúde, serviços e tecnologia 2a ed. Brasília, DF: Ministério da Saúde; 2004.

14. Morais, FRM, Jales GML, Silva MJC, Fernandes SF. A importância do PET-Saúde para a formação acadêmica do enfermeiro. Trab Educ Saude. 2012;10(3):541-51. http://dx.doi.org/10.1590/S1981-77462012000300011.

15. Moscovici F. Desenvolvimento interpessoal: leitura e exercícios de treinamento em grupo. Rio de Janeiro: Livros Técnicos e Científicos; 1985.

16. Feuerwerker L. Micropolítica e saúde: produção do cuidado, gestão e formação. Porto Alegre: Rede UNIDA; 2014. (Coleção Micropolítica do Trabalho e o Cuidado Saúde). 


\section{Minicurrículo}

Mara Lúcia Renostro Zachi | ORCiD: 0000-0006486-7760

Mestre em Ensino das Ciências da Saúde pela Faculdades Pequeno Príncipe em Curitiba, PR. Especialista em Vigilância Sanitária e Epidemiologia em Saúde, pela Universidade Paranaense. Especialista em Processos Educacionais na Saúde com Ênfase em Tecnologias Educacionais Construtivistas Pelo Instituto Sírio-libanês de Ensino e Pesquisa. Graduada em Enfermagem Pela Universidade Paranaense. Enfermeira da Secretaria Municipal de Saúde de Cascavel, PR, Brasil.

Elaine Rossi Ribeiro | ORCiD: 0000-0003-3492-217X

Doutora em Clínica Cirúrgica pela Universidade Federal do Paraná. Mestre em Educação pela Universidade Estadual de Londrina. Docente e Pesquisadora da Faculdade Pequeno Príncipe em Curitiba, PR e do Programa de Pós Graduação Strictu Sensu - Ensino nas Ciências da Saúde. Participante do Grupo de Pesquisa PENSA.

Maria Lucia da Silva | ORCiD: 0000-0002-3352-8069

Doutora em Ciências pela Universidade Federal do Rio de Janeiro. Mestre em Saúde Coletiva pela Universidade Estadual do Paraná de Londrina. Coordenadora e professora de cursos de Pós-graduação Lato Sensu do Instituto Filadélfia - UNIFIL. Enfermeira da Secretária Estadual de Saúde do Paraná.

Rogério Saad Vaz | ORCiD: 0000-0002-7537-5320

Doutor em Engenharia de Bioprocessos e Biotecnologia pela Universidade Federal do Paraná. Gestor de Núcleo de Internacionalização do Complexo Pequeno Príncipe. Pesquisador do Programa de Mestrado em Ensino nas Ciências da Saúde da Faculdade Pequeno Príncipe. 